\title{
ФЕНОМЕН ДУХА В ФИЛОСОФСКОЙ АНТРОПОЛОГИИ
}

\begin{abstract}
Аннотация. Существует довольно распространенное мнение о том, что философская антропология теснейшим образом связана с культурой. Нет смысла говорить о человеке вне культуры. Отчасти это утверждение справедливо. Однако культура указывает на определенный способ бытия. Многие антропологи и культурологи не задаются целью выяснить, почему таков человек, что представляет собой его экзистенциальная реальность, в которой проявляется его детерминированная оригинальность. Сведение всей проблемы человека к описанию культуры означало бы невнимание к основной стороне вопроса: что определяет культурную сущность человека?

Ключевые слова: психология, философская антропология, духовность, человек, история, дух, знание, объективный дух, культура, свобода.
\end{abstract}

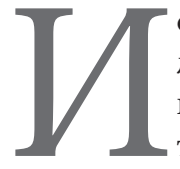

сследование проблемы человека предполагает, судя по всему, удерживание в поле внимания трех взаимосвязанных аспектов: исторического, психологического и философского. Люди живут в истории. Она находятся в настоящем, но сохраняют связь с прошлым. Прошлое человека не было напрасным. Если объять его в целом и выделить из него те нити, из которых складывается человеческая реальность, проследить постепенное развитие человека до существующего в данный момент «Я», изучить тщательно свое собственное сознание, то проблема человека станет более ясной.

Другая неотъемлемая характеристика человека - его психика. Человек - совокупность страстей, вожделений, импульсов, устремлений. Некоторые авторы полагают, что они создают философскую антропологию, собирая научные факты, используя правила теоретической рефлексии. Они хотят сделать философскую антропологию сугубо научной. Это относится, например, к работе А. Адлера «Понять природу человека»'. «Теперь нам предстоит объяснить, почему мы пытаемся подойти к проблеме природы человека с точки зрения медицинской

1 Адлер А. Понять природу человека. СПб., 1997. науки, - писал Адлер, - имея целью заложить основы точного научного знания в этой обширной и посему не поддающейся точному исследованию области. Также мы рассмотрим предпосылки к созданию подобной науки о природе человека и определим, какие проблемы она должна разрешить и каких результатов от нее следует ожидать»².

Вопрос о человеке нельзя решить, если исходить только из сведений биологии, физики, психологии или социологии. М. Бубер в работе «Проблема человека» отмечает, что только из данных наук невозможно выяснить, что представляет собой человек. «Вокруг того, что обнаружит в себе осознающий себя философ, писал он, - должно строиться и кристаллизоваться, чтобы стать подлинной философской антропологией, и всё то, что он найдет у людей настоящего и прошлого - у мужчин и женщин, у индейцев и жителей Китая, у бродяг и императоров, у слабоумных и гениев. Но это совсем не тот случай, когда, предположим, психолог на основании изучения самого себя, через самонаблюдение, самоанализ и эксперимент над собой дополняет и разъясняет всё то, что он узнал из книг и наблюдений

2 Там же. С. 7.

Статья подготовлена при поддержке гранта РГНФ №12-03-00574a "Духовность как проблема современной культуры" 
Мотивация и духовность личности

иного рода. Ведь речь шла бы тогда об отдельных объективированных процессах и феноменах, об извлеченной из контекста целостной живой личности» ${ }^{3}$.

Философская антропология отличается от других дисциплин, исследующих человека в каком-либо одном аспекте, своей целостностью. Философские антропологи хотят уловить, по меньшей мере, живую целостность личности, ее конкретное «Я». Узнать целостную личность он сможет лишь в том случае, если не упустит из виду свою субъективность и не превратится в бесстрастного наблюдателя. Философская антропология более решительно, чем, скажем, гештальт-психология, находит в человеке конфигурации и поведение, которые невозможно расчленить и подвергнуть конечному анализу.

К числу базовых человеческих экзистенциалов, безусловно, относится духовность. Понятие «дух» в философской антропологии имеет длительную и своеобразную историю. С незапамятных времен неотъемлемыми качествами человека считались свобода, рефлексия, дух. Дух - это высшая способность человека, позволяющая ему стать субъектом смыслополагания, личностного самоопределения, осмысленного преображения действительности. Мы, люди, представляем собой наличное бытие, сознание вообще и дух, то есть движимую идеями целостность доступных пониманию связей в нас самих и во всем том, что нами сотворено, осуществлено и помыслено.

В христианстве теология и антропология идут рука об руку. Христианизированные платонизм и неоплатонизм только делают вид, что проводят различие между чувственным и духовным. Августин Блаженный - это величайший пример того, как человек находит себя самого в духовной сфере. Огромный вклад этого мыслителя в философское постижение человека заключается в тенденции к интроспекции. «Это изумление человека перед самим собой, которого Августин добивался от самопознания - совсем не то чувство, с которого Аристотель, будучи еще в кружке Платона, призывал начинать всякое рассуждение. Человек Аристотеля, наряду со всем остальным, восхищается и человеком, но лишь как частичкой, во всех отношениях достойной восхищения Вселенной. Человек Августина изумляется в человеке не тому, что должно быть осмыслено как часть Вселенной и как вещь среди вещей. Если восхищение первого давно переродилось в метафизическое философствование, то изумление второго впервые являет себя во всей глубине и тревоге. Это не философия, но она окажет воздействие на всю будущую философию» ${ }^{4}$.

3 Бубер М. Проблема человека // Бубер М. Два образа веры. М., 1995. С. 163-164.

4 Там же. С. 166.
Образ мыслей Канта и решение им философских проблем основывается на предположении, что всякая наука, особенно философская, должна быть наукой о человеке, всякое достижение науки помогает человеку лучше познать себя. В работе «Антропология с практической точки зрения» Кант пишет о том, что «человек, сам себя изучающий, составляет важный предмет познания, так как через него можно познать вселенную. Такая антропология рассматривается как знание мира» ${ }^{5}$.

В «Критике чистого разума» Кант уделяет в антропологии гораздо больше внимания человеку ${ }^{6}$. Лишь у Канта впервые появляется критическое осмысление антропологической проблематики. Оно становится ответом на жизненно важные требования Паскаля. И хотя ответ этот носит не метафизический, а эпистемологический характер и имеет в виду не бытие человека, а его отношение к миру, в нем все же запечатлены и фундаментальные проблемы: что есть мир, который познает человек? Как вообще может познавать мир человек в его конкретной действительности? В каком отношении находится он к этому, тем или иным способом познаваемому им миру? Что этот мир человеку и что ему человек? Самоанализ приближает нас к тому, что мы понимаем под духом. Гегель, Шелер и многие другие указывали на динамику духа. В этом утверждении содержится большая доля истины, потому что дух постигает только тот, кто чувствует в себе его присутствие и развивает его в себе. Это скрытое сокровище, цену которого мы узнаем в процессе развития нашего внутреннего содержания при помощи размышления и сосредоточенности. Некоторые личности утрачивают свои духовные свойства, будучи неспособными к развитию личной независимости и свободы. Неорганические, органические, вегетативные и животные основы человека отчасти препятствуют его духовному развитию. Однако, наряду с этим, они способствуют его росту, превращаясь в цель его деятельности, или в объективность, составляющую субъективное условие духа.

Несмотря на свою свободу, дух не может избежать обусловленностей. Мы ощущаем их в нашей деятельности. Дух развивается и проявляется во временной и пространственной обусловленности. Мы делаем различие между простым фактом нахождения в пространстве и во времени - единственный способ существования людей и природы - и тем, как на нас влияет

5 Кант И. Антропология с прагматической точки зрения // Кант И. Собр. соч.: в 8 т. Т. 7. М., 1994. С. 139.

6 Кант И. Критика чистого разума // Кант И. Собр. соч.: в 8 т. T. 3. М., 1994. 


\section{Психология и психотехника 1(52) • 2013}

пространство и время, или тем, как мы реагируем на эти условия. Нечеловеческая природа существует и действует в пространстве и во времени совсем по иному, чем человеческая.

Человек существует в пространстве и времени сознательно. Случайность может поместить человека здесь и сейчас, но человек освещает эту случайность своим знанием. Мы отличаем время от пространства. Но они действуют в человеке как нераздельная пара. Не существует времени, сосредоточенном в нем самом. Время влияет на что-либо или присутствует в чем-либо или в ком-либо. Пространство ощутимо и познаваемо только во времени. Пространство само по себе, неподвижное и пассивное, лишено смысла. Ни одна точка пространства не обладает реальностью, если она не существует в детерминированном времени. Вследствие этой пространственно-временной обусловленности каждое существо представляет собой концентрическую точку во вселенной. Пространство и время как бы формируют структуру человека, а когда дух действует активно, они препятствуют его развитию. Время и пространство, которые мы ощущаем, превращают людей в существа исторические и обусловленные. Быть историческим существом значит видеть себя звеном одной цепи, возникающей в настоящем, связанным с прошлым и подготавливающим будущее.

Вещи безразличны к течению времени. Животные отождествляются с их настоящим, с их здесь и теперь, человек же анализирует свое присутствие во времени. Время и пространство его не подавляют. Он является их составной частью. Он ощущает их непрерывность и находится в этой непрерывности не пассивно, а как активное и ответственное существо. Он освещает из своей действительности прошлое и будущее, понимает, как они влияют на его существование во времени. От него зависит, отдаться ли на волю течения времени или быть активным.

Человек способен наблюдать за своим временем и пространством, использовать их и даже во многом управлять ими. Одно из самых больших достижений духа - осознание человеком себя как существа исторического.

Доказательством сходства человека с высокоорганизованными животными служит тот факт, что они пользуются символами. Различие же в применении символов состоит в том, что человеческие символы, в силу их прогрессивной эволюции, кажутся столь свободными, что хочется поместить их в совершенно новую сферу природы.

Мы всегда сохраняем связь с природой. Нет такого языка, который был бы целиком свободен от остатков мифа. Язык - это система знаков, подобная мимике, но более сложная, менее совершенная, чем то, что человек способен воображать. Он не может быть адекватным и логическим выражением мышления. Слова - это скорее продукт воображения, чем абстракции. Они функционируют как посредники между конкретной действительностью и мышлением, между абстрактным мышлением и конкретными людьми, к которым они направлены. То, что человек - существо говорящее, создает серьезные трудности для эволюционистов, утверждавших, что все человеческие свойства зародились на первичном животное этапе.

Язык самых примитивных человеческих групп и народов, чьи следы теряются в далекой истории, уже совершенен и грамматически завершен, хотя, естественно, беден в терминологии. Нет языков застывших. Язык - явление историческое, и он эволюционирует, как человек, использующий его для коммуникации. Язык - феномен сугубо человеческий. Ребенок прежде чем его органы речи готовы к произнесению слов, не может не болтать. Профессор У.Н. Келлог и его жена вырастили маленького шимпанзе. Они обращались с ним, как со своим сыном. Однако у шимпанзе не появилось никакого признака лингвистической выразительности. Человек, оказавшийся в полном одиночестве, сохраняет способность говорить, но она у него не развивается, так как он лишен среды. Язык - человеческий инстинкт, но его оформление и развитие зависит от социальной среды.

Значительную роль в философском постижении человека сыграл Гегель. «Индивид имеет бесконечную ценность», - писал он в «Философии религии» ${ }^{7}$. Полагая, что человек обладает бесконечной ценностью, он отмечал, что он является целью в себе самом благодаря своему божественному началу. «Бог есть бог лишь постольку, - писал Гегель, - поскольку он знает самого себя; его знание самого себя есть, далее, его самосознание в человеке» ${ }^{8}$. Заслуга немецкого философа состоит в том, что он анализировал проблему человека в онтологическом аспекте через общее понимание мира, его природы и его абсолюта.

Если не знать всей системы размышлений Гегеля, а иметь о ней лишь частичное представление, то можно заключить, что этот немецкий философ - убежденный эволюционист, воспевающий свободу. Гегель действительно утверждает, что история в процессе эволюции стремится к победе духа и свободы, но это только слова, которые имеют смысл в приложении к целостности

Гегель Г.В.Ф. Философия религии: в 2-х т. М., 1975. Т. 2. C. 297.

8 Гегель Г.В.Ф. Энциклопедия философских наук. М., 1977. T. 2. C. 389. 


\section{Мотивация и духовность личности}

или к абсолютному духу, проявляющемуся в различной форме в пространстве и во времени. Только в нем универсальная история обретает смысл. В приложении же к повседневной человеческой деятельности, где возникают труднопреодолимые препятствия и различные альтернативы, они неприменимы. Историю и индивидов, которые являются ее неотъемлемой частью, Гегель представляет как простое проявление абсолютного духа и при этом полагает, что каждая отдельная форма абсолютного духа, возникшая исключительно по его требованию и к его услугам, - явление временное и подлежащее уничтожению.

Шопенгауэр был одним из первых философов, приблизивших теорию эволюции к исследованию вселенной. Однако его система соответствует еще той эпохе, когда открытие подобия человека природе означало рост познания. Шопенгауэр утверждает, что существует уникальная вещь в себе, отправной пункт энергии, вслепую ведущий вперед динамику, составляющую жизнь. Эта энергия присутствует как в человеке, так и в природе. Теория Шопенгауэра и другие, подобные ей, показывают, что философ может увлечься частными достижениями своей эпохи.

А. Бергсон считает, что дух первичен, что он действует как средство и достигает своего совершенства в цели. Он сопровождает действительность и животную жизнь, и с зарождением бытия стремится ко все большей автономии. Подобная концепция духа может считаться финалистской. Бергсон, указывая путь к познанию человека, считает, что нельзя обойти молчанием проблему сознания животного мира. Французский ученый Лекон дю Нойю вслед за ним подчеркивает, что вся судьба человека заключена в его духе. Мир существует для духа и его формирует. Он предполагает, что дух подчинен определенному закону или определенным духовным силам. А. Портман утверждает, что идея духа преобразует не только наше понятие человека, но понятие природы и жизни. Теория эволюции, глубокое проникновение в психологию помогает прояснению этих понятий. Он утверждает, что уже в протоплазме угадывается единая, никогда не прерывающаяся деятельность, что протоплазма - это еще плохо исследованный феномен. Духовный процесс сопровождает процесс жизненный и в конце концов достигает высшего уровня в человеке. Поэтому человек всегда есть нечто большее, чем можно сказать о нем в данный момент.

Дух не существует без природы, он присутствует в природе, но не равен ей. В пределах своей науки биологи не могут сказать ничего большего. Однако и этого достаточно для познания человека. Познание духа занимает в философии центральное место. Без него философская антропология утратила бы смысл. В истории философии можно назвать две тенденции: одна уничтожала личность, превращая ее в проявление абсолютного духа. Другая сводила концепцию духа к его выражению в индивидуальности человека. Эти две тенденции идут разными путями, но приходят к одному выводу - к отрицанию «Я», сознания, личности. В. Дильтей, М. Шелер, Н. Гартман разделяют по сути дела взгляд биологов, которые приписывают духу исключительно материальное происхождение.

Самое основное свойство живых организованных существ - память. Инстинкт животного достигает такого совершенства, что создает новую форму. Но она у животных не имеет черт индивидуальности, а действует у них как традиция, свойственная всему виду, как его основное содержание. Она и есть непосредственный источник возникновения человеческой сферы. Дж. Гексли характеризовал человека как существо чисто животное, но столь оригинальное и своеобразное, что оно сказывается в природе явлением уникальным и отчужденным.

А. Портман, определяя своеобразие человека, отмечал, что общее между человеком и высшими животными является явным свидетельством того, что все живое составляет одно целое. Биология, считал он, показывает, что биологическая генетика в человеке осуществляется благодаря процессу селекции, в ходе которого жизненные формы человеческого типа преобразуются гораздо быстрее, чем это происходит в природе. Это связано с влиянием традиции и духовной сферы.

Можно позавидовать той уверенности, с какой философы предшествующих эпох создавали свои системы. Николай Гартман в работе «Новый путь к онтологии» указывал, что прошло время построений великих систем. Теперь нужно довольствоваться тем, что всякий прогресс с учетом духовной сферы означает исправление ошибок и в этом состоит внутренний смысл очевидной относительности истины».

Нужно быть признательным Э. Гуссерлю за то, что он почти один в культурном окружении, подчиненном влиянию психоанализа и социологии, подчеркивает единственность и важность субъекта. Он полагает, что нет действительности вне всякого сознания. Это было бы изобретением пустоты. Объект присутствует во всех наших мыслях и поступках. Хайдеггер, Сартр и другие экзистенциалисты постоянно подчеркивали, что нужно ценить нашу единственность. Поставить проблему личности - это значит увидеть, что она окружена бесконечным рядом опасностей. Автономность «Я» требует почти одновременной двоякой деятельности: внимания к самому себе, постоянного осознания, что «Я»- хозяин своей жизни. Относи- 


\section{Психология и психотехника 1(52) • 2013}

тельно нормальный человек только в незначительной мере теряет свое «Я», или свою личность. Если исчезнет личность, то исчезнет человеческий род, человек опустится до уровня животного.

Можно рассматривать человека как целостность, помогающую познать вселенную. Э. Гуссерль в значительной степени упрочил положение философской антропологии. Он показал, что она помогает развитию и углублению феноменологической психологии. Гуссерль отмечал, что самое существенное свойство человека - его способность быть одновременно субъектом и объектом. Эта способность находит свое выражение в языке. Она объясняет преднамеренность и целенаправленность человеческой деятельности.

Философскую антропологию можно рассматривать как универсальную дисциплину о человеке. Гуссерль отводил философской антропологии центральное место среди философских дисциплин и считал, что она ближе других стоит к точным наукам и не должна заниматься интимной сферой человека.

М. Шелер утверждает, что никогда человек не был столь проблематичным, как сегодня. Философская антропология - это не сумма и не энциклопедия всех наук. Но она обязательно включает в себя, прямо или косвенно, весь человеческий прогресс, достижения всякого рода областей знания, связанных с исследованием человека. В философской антропологии человек познает себя не как абстракцию, а в своей экзистенции. Самопознание служит не только целью, но и методом. Человеческой субъективности постоянно угрожает уничтожение. Человек - существо, в высшей степени предварительно сформированное. Поэтому человек всегда стоит перед опасностью сделать объективной истиной то необъективное, что он собой представляет. В философской антропологии исследование идет по кругу, и чем ближе исследователь подходит к объекту исследования, тем труднее кажется ему достижение центральной точки.

Шелер недооценивает первый этап развития биологической и неорганизованной формы. Он считает, что все последующие достижения возникли почти случайно. На самом же деле для этого этапа было характерно очень интенсивное и решительное предформирование и тенденция к высшим формам. Из этого следует, что жизнь не была результатом слепой эволюции. Она протекает очень медленно и сдержанно в растениях и получает большую свободу в животном мире, особенно в его высокоорганизованных видах. Существует внутренняя связь между различными природными существами. Эволюция представляет собой удивительную панораму постоянного роста. Растительная жизнь достигает кульминации в жизни животной. Последняя подготавливает появление человека. Однако тот факт, что человек вышел из животного мира и что он нуждается в нем, не оправдывает никак отождествления человека с животным.

Система А. Бергсона доказывает необходимость предварительного существования животного мира для возникновения человека и для дальнейшего отхода от этого мира. М. Шелер раскрывает своеобразие поведения животных. Чисто животное поведение, выраженное в инстинктах, является следствием деятельности физиологического организма, выражающейся в свойствах психики. Животное не способно превзойти требования животного сообщества или существовать вне него. Оно живет в постоянном подчинении и не противопоставляет себя ему.

Ф. Кордон в ряде очерков исследует тенденции некоторых натуралистов к объяснению высших факторов или к отрицанию закономерности исследования дочеловеческих уровней с позиции человека. Они являются жертвами фетишизма, потому что не проводят различие между орудиями познания действительности и самой действительностью. А. Бергсон заставил изменить такую трактовку человека натуралистами. Он отметил, что ученые сделали многое в освещении этой проблемы, но они подвергали скудному анализу самого человека. Бергсон показал, что действительность, начиная с неорганической материи, борется за свободу и за приобретение осмысленности. Жизнь расширяется и порождает множество разнообразных существ. Благодаря мышлению человек становится самым сильным существом вселенной. Он не только пользуется, но и управляет ею. Мышление дает ему независимость и власть над природой, но не превращает его в существо другой сферы и не открывает ему тайну природы.

По мере того, как экспериментальная биология, генетика и теория эволюции доказывает своеобразие человеческого существа, возникает потребность говорить об антропологии происхождения. Она может показать, что нельзя делать категорических выводов перед лицом глубокой тайны, окружающей смысл жизни. Если нет стремления осознать смысл жизни, то возникает ощущение пустоты человеческой экзистенции. Эта хорошо обоснованная доктрина, концентрирующая внимание на человеке, способна показать, что с подъемом уровня организованности живого растет особая ценность индивида в той мере, в какой увеличивается возможность индивидов к осуществлению общих целей.

Иногда философы наделяют понятие «дух» отрицательным смыслом. «Редко с каким словом творили столько безобразий, - писал Шелер, - и лишь немногие понимают под этим словом что-то определенное» ${ }^{9}$

9 Шелер М. Избранные произведения. М., 1994. С. 153. 


\section{Мотивация и духовность личности}

Однако трудно найти более подходящий термин для выражения следующей мысли: человек познает, потому что он есть духи, или, иными словами, человек обретает себя самого и противопоставляет себя действительности. Благодаря тому, что дух составляет часть нашего существа, мы кажемся себе хозяевами нашей экзистенции. Дух - путеводитель и смысл нашей жизни.

Стремление человека к свету М. Шелер в книге «Метафизика свободы» почти отождествляет с идеей Бога. Человек как абсолютное целое, содержащий в себе все человеческие свойства всех человеческих историй в эмпирическом смысле, нам также близок и так же далек от нас, как Бог, потому что мы воспринимаем дух и жизнь, как два его атрибута, - они и есть сущность человека, только в бесконечной форме. «Для нас основное отношение человека к мировой основе состоит в том, - писал Шелер, - что эта основа непосредственно постигает и осуществляет себя в самом человеке, который как таковой и в качестве духовного, и в качестве живого существа есть всякий раз лишь частичный центр духа и порыва, принадлежащих «сущему через себя» ${ }^{10}$.

В более метафорическом смысле справедливо говорить об объективном духе и даже об абсолютном духе. Первый, отождествленный с культурой, представляет собой сумму вкладов, внесенных различными личностями. Абсолютный дух включает в себя как культуру, так и ее творцов, и взаимосвязи, которые существуют между ними. Название «абсолютный дух» дается также наивысшему существу, способному воплотить в себе всю объективированную культуру нашей индивидуальной души.

Говоря о конкретном человеке, о том, что собой представляет каждый из нас, мы подходим, вероятно, к центру философской антропологии. Существуют четыре взаимосвязанных термина, которые предполагают друг друга и во многом кажутся близкими. Каждый из них отражает нечто чисто человеческое. Они показывают, как воспринять себя как существо, отличающееся от других.

Первый термин «Я». Это слово обладает столь индивидуальным содержанием, что заставляет человека осознавать его уникальную и отличную от других экзистенцию. Когда говорят «Я», противопоставляют себя всякой другой реальности. Это возможно благодаря второму термину - «сознание», которое в своем основном и психологическом смысле есть ясность, сконцентрированная в «Я». Все остается в темноте, как не принадлежащее мне, как чуждое. Третий термин «личность», в которой проявляется моя автономная сущность как обладающая сознательным «Я», свобод-

10 Шелер М. Избранные произведения. М., 1994. С. 190. ным и ответственным. Центром всех человеческих актов Шелер называл личностью, четко отличая ее от всех функциональных «жизненных» центров, которые, при рассмотрении их с внутренней стороны, называются также «душевными» центрами.

Эти понятия - корни одной и той же действительности, подразумеваемой под названием субъективного духа или чистого духа. Они не являются функциями духа, а составляют его. Можно говорить о свойствах чисто духовных, поскольку без них нет ни «Я», ни сознания, ни личности. Эти свойства следующие: разум, способность видеть и анализировать то, что не есть мое «Я» или что является объектом по отношению ко мне. С разумом связана способность абстрагирования. Благодаря этой способности человек не только познает мир, но и пользуется им.

Интеллектуальный процесс и абстрагирование лишены смысла, если отсутствует память и воображение. У человека эти свойства соединены с чувством осознания своей личности. Моя память, память каждого человека есть хранилище опыта и познания, уникальных для меня, заставляющих меня быть именно самим собой перед остальными. Это возможно благодаря самому совершенному духовному свойству - свободе. «Я» принимает и отвергает.

Итак, «Я», сознание, личность и дух соотносятся с одной действительностью. Описать ее все равно, что раскрыть ее. Мы ощущаем «Я» в сознании заключаем его в понятие личности; сознание раскрывает «Я» и отличает нас как личностей. Мы чувствуем себя личностями в сознании, в том, как выражается «Я». Мышление, благодаря его способности к абстрагированию, обладает самым широким и практическим свойством интерпретации прошлого и предвидения будущего. Этому помогает способность памяти сохранить в себе опыт и координировать его. Лишенный такой памяти человек руководствовался бы в своей деятельности случайностью. Он лишился бы свободы и не мог бы бороться с непредвиденными обстоятельствами. Каждый из нас личность, если он свободен. Как только человек понимает, что он есть дух, он превращается в хозяина себя самого. Только поняв себя, он способен познавать и то, что не есть он.

М. Хайдеггер представляет дух как действующий. Он предполагает у него такие свойства, как самопринадлежность, свободу и сознание. «Тело человека, - пишет Хайдеггер, - есть нечто принципиально другое, чем животный организм. Заблуждение биологизма вовсе не в том, что люди надстраивают над телесностью человека душу, над душой дух, а над духом экзистенциальность и громче прежнего проповедуют великую ценность духа, чтобы потом, однако, все снова утопить в жизненном 


\section{Психология и психотехника 1(52) • 2013}

переживании, с предостерегающим утверждением, что мысль-де разрушает своими одеревенелыми понятиями жизненный поток, а осмысление бытия искажает экзистенцию» ${ }^{11}$.

Если физиология и физиологическая химия способны исследовать человека, отмечает немецкий философ, в естественнонаучном плане как организм, то это еще не доказательство того, что в такой «органике», т.е. научно объясненном теле, покоится существо человека. Это ничуть не удачнее мнения, будто в атомной энергии заключена суть природных явлений. Может, наоборот, оказаться, что природа как раз утаивает свое существо в той своей стороне, которой она поворачивается к технически овладевающему ею человеку. Насколько живое существо не сводится к животной органике, настолько же невозможно устранить или как-то компенсировать недостаточность этого определения человеческого существа, наделяя человека бессмертной душой, или личностными качествами.

М. Хайдеггер полагал, что нельзя расширять философскую антропологию настолько, что она утрачивает свою сущность. Он подчеркивал, что с истолкованием человека как субъекта Декарт создает метафизическую предпосылку для будущей антропологии всех видов и направлений ${ }^{12}$. В восхождении антропологий Декарт, по слову философа, празднует свой высший триумф. Благодаря антропологии начинается переход метафизики в процесс элементарного превращения и оставления всякой философии. Хайдеггер считал, что В. Дильтей отрицал метафизику, по существу он не понимал ее вопроса и беспомощно противостоял метафизической логике. Это оказалось внутренним следствием его антропологической установки. Работу В. Дильтея «Философия философии» Хайдеггер называет благородной формой «антропологического упразднения» ${ }^{13}$.

Зато, как показывает Хайдеггер, у всякой антропологии, в которой прежняя философия, хотя и используется по желанию, но как философия объявляется излишней. По крайней мере появляется ясность, что в этом случае постулируется принятие философской антропологии. Вместе с тем одного не может дать эта антропология - преодолеть Декарта или хотя бы восстать против него. Следствие не может пойти против причины, на которой она стоит. Для Декарта человек есть мера всего сущего. «При более серьезном осмыслении, - писал Хайдеггер, - оказывается, однако, что субъективность обусловлена существом истины как «достоверности» и бытием как представленностью. Мы

11 Хайдеггер М. Время и бытие. М., 1993. С. 198.

12 Там же. С. 54.

13 Там же. видели, как развертывается представление в полноте его существа и как лишь внутри него - как лежащего в основе - человек, прежде всего, как «Я», превращается в субъект в более узком смысле. Что человек при этом становится исполнителем и распорядителем и даже обладателем и носителем субъективности, никоим образом не доказывает, что человек есть сущностное основание субъективности» ${ }^{14}$.

Вопрос можно вслед за Хайдеггером поставить так: не является ли всякое истолкование человека и тем самым историческое бытие человека каждый раз лишь сущностным следствием того или иного «существа» истины и самого бытия? Если дело обстоит так, то существо человека, по Хайдеггеру, никогда не может быть определено с достаточной изначальностью через прежнее, то есть метафизическое истолкование человека как разумного живого существа.

В книге Хайдеггера «Бытие и время» сделана попытка на основе вопроса об истине бытия, уже об истине сущего, определить существо человека из его отношения к бытию и только из этого отношения. Почва непонимания лежит, прежде всего, в неискоренимой, упрочивающейся привычке к новоевропейскому образу мысли. Человек мыслится субъектом. Всякое осмысление человека понимается как антропология. С другой стороны, почва непонимания заложена в самой предпринятой попытке, которая, будучи все же, наверное, чем-то исторически выросшим, а не «сделанным», исходит из прежнего, но от него отрывается и тем самым неизбежно и постоянно все еще отсылает на прежнюю колею.

По мнению Б. Рассела, дух - всего лишь слово, лишенное собственного смысла и содержания, потому что нет различия между духом и материей, как нет различия между психологией и физикой. Обе эти дисциплины различаются, по мнению Рассела, только потому, что физика собирает конкретный материал, исходя из активных источников, а психология - из пассивных. Они представляют собой логические конструкции. Рассел приходит к заключению, что дух - это память, в которой кристаллизуется своеобразие накопленного личного опыта.

Э. Кассирер подчеркивал, что язык связан с духом и зависит от него. Речь, включая звукоподражание, символична. Это самый сложный символ, поскольку язык должен обладать способностью превращаться в средство или приобретения каждым человеком разнообразного опыта, для отображения связей между людьми и между материальной и духовной действительностью. Однако язык не есть средство, которое

14 Там же. С. 144. 
Мотивация и духовность личности

в совершенстве передавало бы другому наши мысли, и никогда не может стать им. Каждый человек в его духовной сущности представляет гораздо больше того, что он может сообщить. Язык показывает, что в каждом человеке имеется много социального. Каждая сфера человеческих отношений имеет свой язык, от интимного до национального. Однако остается одна область - внутренний мир человека, которую нельзя выразить символически. Люди часто стараются сделать это, но напрасно, потому что обычные слова для этого не подходят. Особенно остро это положение чувствует поэт, когда он хочет сообщить о том, что происходит внутри него. Истинное слово, полное исчерпывающего значения, еще не было произнесено, между людьми.

Язык - продукт культуры, отражающий ее качество и глубину. Он передает определенный способ понимания и интерпретации человеком его окружения. Человек на протяжении своего существования в большой мере зависит от того, какой он усвоил с детства язык. Ему свойственна определенная манера бытия и мышления. Язык способен создавать культуру. Человеческий дух в контакте с космосом, складывает и воображает формы, тревожащие природную неподвижность, или изобретают неожиданные варианты. Эти формы вначале носят минутный и непостоянный характер, а затем превращаются в привычки или традиции. Человеческий индивид творит язык, науку, искусство, обычаи. Каждый человек причастен к творению культуры.

Каждый человек представляет собой уникальный экземпляр. Он знает, что он неповторим. В человеке происходит внутренний процесс, который невозможен для нечеловеческого существования. Ему предназначены его собственные время, пространство, условия, в которых протекает его развитие. Человек говорит: я это «Я», а не кто-то другой. Сколь бы ни были близки мы к нашей семье, к окружающей нас среде, даже если мы считаем себя в какой-то мере неотделимыми от них, мы не отождествляем себя с ними. Анализы категории времени также подтверждают нашу неповторимую единственность. Мое «сегодня» принадлежит столь исключительно мне, что оно отличается от «сегодня» других, окружающих меня, и скрыто от них. Человек - это всегда «Я».

Система В. Франкла отчасти подпадает под эту характеристику. Он различает тело, душу и дух. Духовный мир - это центр сознания, ответственности и свободы, противостоящей требованиям природы. Возвеличивание человека начинается с того момента, когда он открывает свое присутствие в этом внутреннем мире и чувствует себя по-другому, более возвышенно, чем в психологической сфере. «Так что же такое, наконец, это соприсутствие духовного сущего? Это интенцио- нальность этого духовного сущего! Духовное сущее, однако, интенционально по своей сущности, и можно тем самым сказать: духовное сущее - это духовное существующее, это сознающее бытие, оно соприсутствует иному сущему, сознавая иное сущее. Таким образом, духовное сущее реализует себя в соприсутствии, и это соприсутствие духовного сущего является его исконной способностью, его собственным первейшим достоянием» ${ }^{15}$.

«Психическая жизнь, - считал К. Ясперс, - вовлечена в беспрерывный процесс самообъективации. Она проявляется вовне благодаря таким неотъемлемо присущим человеку потребностям, как потребность в действии, потребность в самовыражении, потребность в представлении и потребность в общении. Наконец, в свои права вступает чисто духовная потребность желание воочию увидеть сущее, себя самого и все то, что было обусловлено остальными фундаментальными потребностями. Это последнее усилие по объективации может быть сформулировано в следующих словах: то, что обрело качество объективности, должно быть постигнуто и сформировано как некая общая объективность более высокого порядка. Я хочу знать, что же именно я знаю, и понять, что же именно оказалось доступно моему пониманию» ${ }^{16}$.

Основной феномен духа, по К. Ясперсу, состоит в том, что он вырастает на психологической основе, но сам по себе не имеет психической природы. Это объективный смысл, мир, принадлежащий всем. Отдельный человек обретает дух только благодаря своему соучастию в обладании всеобщим духом, который передается исторически и дан человеку в форме, соответствующей каждому данному моменту времени. Всеобщий или объективный дух постоянно присутствует и проявляет себя в обычаях, идеях и нормах общественной жизни, языке, достижениях науки, искусства, поэзии, а также во всех общественных институтах.

Любопытно, что значимая субстанция объективного духа не подвержена болезни. Но болезнь отдельного человека может иметь в качестве своей первопричины то, как именно этот человек соучаствует в жизни объективного духа и воспроизводит этот дух. Более того, почти все нормальные и аномальные события психической жизни так или иначе оставляют своего рода «осадок» в сфере объективного духа - в зависимости от того, каким образом объективный дух проявляет себя в том или ином человеке.

Другое фундаментальное феноменологическое качество духа состоит в следующем: для души существует

15 Франкл В. Человек в поисках смысла. М., 1990. С. 95.

16 Ясперс К. Общая психопатология. М., 1997. С. 352. 


\section{Психология и психотехника 1(52) • 2013}

только то, что обрело объективно-духовную форму; с другой стороны, то, что обрело эту форму, обрело в то же время особого рода реальность, которая оставляет свой отпечаток в душе. То, что однажды стало словом, превращается в нечто непреодолимое. Став реальностью благодаря духу, душа одновременно вводится в некоторые пределы.

Наконец, еще одно фундаментальное феноменологическое качество духа, по Ясперсу, состоит в том, что он может стать реальностью, только если его принимает или воспроизводит душа. Истинность этой духовной реальности неотделима от аутентичности тех событий психической жизни, которые служат ее переносчиками. Объективация духа происходит при посредстве структур, речевых форм, разнообразных форм деятельности и поведения. Но истинное воспроизведение может замещаться автоматизмом речи, условной мимикой и жестикуляцией. Истинные символы исчезают, уступая место будто бы известному содержанию суеверий. Аутентичный источник замещается рационализацией.

Личность постоянно находится в опасности. Неизбежные влияния мешают развивать ее так, как человеку хотелось бы. Невозможно выделить такое чистое «Я», которое было бы полностью свободно от влияния факторов, не зависящих от него. Однако неправы авторы, которые умаляют личность, оставляя от нее лишь тень.

Ощущение в своем сознании «Я», независимого и автономного, являются выражением необусловленности. Человек осознает, что он не зависит от общих связей причина-следствие, управляющих физическим миром. Понятие свободы исчезает, когда процесс человеческого развития описывается как подобный развитию продуктов природы. Повседневная жизнь подтверждает, что перед человеком стоит множество препятствий, которые он вынужден преодолевать, побеждать или обходить. Нельзя говорить о свободе воли, если отсутствует «Я», или субъект, который воздействует на объект, преодолевая препятствия. Человеческое бытие сложно. Каждый шаг человека ограничивается условиями и требованиями, предъявляемыми ему природной средой и обществом. Человек почти всегда им подчиняется, потому что невозможно физически и морально вести постоянную борьбу. Однако именно исключения из этого правила формируют нас в подлинных людей.

\section{Список литературь:}

1. Адлер А. Понять природу человека. СПб, 1997.

2. Бубер М. Два образа веры. М., 1995.

3. Гегель Г.В.Ф. Философия религии: В 2-х тт. М., 1975. Т. 2.

4. Гегель Г.В.Ф. Энциклопедия философских наук. М., 1977. Т. 2.

5. Кант И. Антропология с прагматической точки зрения // Кант И. Собр. соч. в 8-и тт. Т. 7. М., 1994.

6. Кант И. Критика чистого разума // Кант И. Собр. соч. в 8-и тт. Т. 3. М., 1994.

7. Франкл В. Человек в поисках смысла. М., 1990.

8. Хайдеггер М. Время и бытие. М., 1993.

9. Шелер М. Избранные произведения. М., 1994.

10. Ясперс К. Общая психопатология. М., 1997.

\section{References (transliteration):}

1. Adler A. Ponyat' prirodu cheloveka. SPb, 1997.

2. Buber M. Dva obraza very. M., 1995.

3. Gegel' G.V.F. Filosofiya religii: V 2-kh tt. M., 1975. T. 2.

4. Gegel' G.V.F. Entsiklopediya filosofskikh nauk. M., 1977. T. 2.

5. Kant I. Antropologiya s pragmaticheskoy tochki zreniya // Kant I. Sobr. soch. v 8-i tt. T. 7. M., 1994.

6. Kant I. Kritika chistogo razuma // Kant I. Sobr. soch. v 8-i tt. T. 3. M., 1994.

7. Frankl V. Chelovek v poiskakh smysla. M., 1990.

8. Khaydegger M. Vremya i bytie. M., 1993.

9. Sheler M. Izbrannye proizvedeniya. M., 1994.

10. Yaspers K. Obshchaya psikhopatologiya. M., 1997. 